\title{
Aetiology of the Lumbar Spinal Stenosis in Black Africans: Intraoperative Observations
}

\author{
Holden O. Fatigba ${ }^{{ }^{*}}$, Aristote A. Hans-Moevi ${ }^{2}$, Mofou Belo ${ }^{3}$, Kofi-M.Savi de Tové ${ }^{4}$, Aicha G. Pape ${ }^{1}$, Moustapha \\ Mijiyawa ${ }^{3}$ \\ ${ }^{1}$ Unit of Neurosurgery, Medicine School of Parakou University, Borgou, Benin, Africa \\ ${ }^{2}$ Department of Surgery, Medicine School of Abomey-Calavi University, Benin, Africa \\ ${ }^{3}$ Medicine School of Lomé University, Togo, Africa \\ ${ }^{4}$ Department of Imaging Diagnose, Medicine School of Parakou University, Benin, Africa \\ ${ }^{*}$ Corresponding Author: Holden O. Fatigba; PO box 2 CHD-Borgou (Benin), Africa, E-mail: holfatigba@gmail.com, Tel.+229.97 49 \\ 2245
}

Article Type: Research Article

Received: April 25, 2015, Last Revised: June 4, 2015, Accepted: June 6, 2015

\section{Abstract}

Background \& Aim: Lumbar spinal stenosis (LSS) is a common condition. This congenital or acquired stenosis has multiple etiologies. The goal of this study was to describe intraoperative pathoanatomic findings of lumbar spinal stenosis observed within a black African population.

Methods \& Materials/Patients: It was a retrospective and descriptive study performed at Departmental Teaching Hospital of Borgou in Republic of Benin (West Africa) from January 2008 to June 2014. All black African patients who underwent surgery for LSS were included. Intra operative aetiologies were recorded. Patients with extruded lumbar discopathy were excluded.

Results: During study period, 199 patients were selected. It was 109 men (54.8\%) and 90 women (42.2\%). Patients mean age was 53.2 years \pm 10.96 , mean weight $77.11 \mathrm{~kg} \pm 14.37$ and mean height $171 \mathrm{~cm} \pm 8.64 \mathrm{~cm}$. The LSS was acquired in 157 patients $(78.9 \%)$, congenital in $29(14.6 \%)$ and in 13 cases $(6.5 \%)$ it was mixed origin. A hypertrophyof ligamentum flavum was observed in 101 patients $(50.8 \%)$, zygapophyseal joint hypertrophy in 15 cases $(7.2 \%)$ and in 74 cases $(37.2 \%)$ the two factors were associated. A disc bulge were observed in 9 cases $(4.5 \%)$

Conclusion: The ligamentum flavum hypertrophy is the main cause of LSS in black Africans. Studies to determine the mechanism of hypertrophy will be useful in order to initiate preventive treatment.

Keywords: Lumbar spinal stenosis; Ligamentum Flavum hypertrophy; Black African; Laminectomy; Zygapophyseal joint hypertrophy

Please cite this paper as: Fatigba O.H, Hans-Moevi A.A, Belo M, Savi de Tové K, Pape A.G, Mijiyawa M. Aetiology of the Lumbar Spinal

.Stenosis in Black Africans: Intraoperative Observations. Iran J Neurosurg. 2015;1(1):35-38

\section{Introduction}

Lumbar canal stenosis is the narrowing of the central diameter of the lumbar canal or of the lateral intervertebral foramen. Stenosis caused by a combination of bone and soft tissues can be acquired or congenital $(1,2)$. In both cases, the result is compression of spinal nerve roots. The compression of nerve roots can be asymptomatic, but it can also become symptomatic. Changes of the ligamentum flavum, of zygapophyseal joint, invertebral discs and osteophytosis are frequently stressed (3). The management of neurosurgical lumbar canal stenosis is a frequent activity in our hospital. A majority of these patients are black (4). The main objective of this study was to describe and report from a surgical series, the intraoperative pathoanatomic finding involved in LSS among black African patients from various countries.

\section{Methods and Patients}

This was a retrospective and descriptive study performed at the Departmental Teaching Hospital of Borgou in Benin (West Africa). The study included patients who underwent surgery for lumbar spinal stenosis from January 2008 to June 2014. All patients were Black Africans. Medical records and operative reports of patients were identified and studied. All pathoanatomic finding observed on imaging and during surgery linked to the narrowing of the canal were recorded. Every spine level involved has been clarified.

The variable studied were patient's origin, age, sex, examination signs, anatomic structure leading to the narrowing of the canal and the postoperative evolution. The causes of the narrowing were considerate as mix when several anatomic elements were involved in the spine stenosis.

In the case of a hypertrophy of anatomic element were predominant, this anatomical element was considered as responsible for symptoms described by the patient. Disc herniation or intra spine cysts cases were excluded in this study. Statistical analysis and data processing were performed with the software epi Info (Version 3.2.2). 


\section{Results}

During the study period, 504 patients were hospitalised for spine disorders in our neurosurgery unit. Among them, 199 (39.5\%) underwent surgical management for a lumbar canal stenosis. They were 109 (54.8\%) men and 90 (45.2\%) women (sex ratio:1.21). Patients' mean age was $53.2 \mathrm{y} \pm 10.96$, the mean weight 77.11 $\mathrm{kg} \pm 14.37$ and mean height of $171 \mathrm{~cm} \pm 8.64 \mathrm{~cm}$ with respective range of 24 and 84 years, 51 and $108 \mathrm{~kg}$ then 157 and $185 \mathrm{~cm}$. They were addressed by a neurologist in 91 cases $(45.7 \%)$, a rheumatologist in 32 cases $(16.1 \%)$, and a general practitioner in 1 case $(0.5 \%)$ and in 75 cases $(37.7 \%)$ patients were recruited during our neurosurgical consultations. The nationality of these 199 patients were 114 Beninese $(57.3 \%)$, 57 Togolese $(28.6 \%)$, 19 Nigerians (9.5\%) and 9 Burkinabe (4.5\%). Amongst the patients operated 148 had an occupation reported in table 1. A radicular pain was observed in all patients and a neurogenic claudication with a progressive reduction of walking perimeter in 173 cases $(86.9 \%)$. This reduction was less than 150 meters in 25 cases $(13.2 \%)$, between 150 and $500 \mathrm{~m}$ in 101 cases $(53.2 \%)$ and between $500 \mathrm{~m}$ and $1 \mathrm{~km}$ in 53 cases (26.6\%). Cauda equine syndrome was present in 10 patients $(5.3 \%)$. The clinical signs observed in patients are reported in Table 2 . The mean duration of symptoms was $3.55 \pm 2.46$ years (range 1 and 15 years). LSS were diagnosed by myelography in 32 cases (16.1\%), a lumbar CT-scan in 161 cases (80.9\%) and Magnetic Resonance Imaging (MRI) in 6 cases $(3 \%)$. According to the imaging data, the stenosis was degenerative in 157 patients $(78.9 \%)$, congenital in $29(14.6 \%)$ and mixed origin in $13(6.5 \%)$ patients (Figure 1). The frequency and percentage of involved lumbar levels were L4, L5, L3-L4, L4-L5 and L3-L4-L5 in 26 (13.1\%), 7(3.6\%), 10(5\%), $101(50.7 \%)$ and $55(27.6 \%)$ cases, respectively. A laminectomy associated with a recalibrate canal was performed in all operated patients. The laminectomy was associated with discectomy in 15 patients $(7.5 \%)$. No arthrodesis or bone fixation was performed. A ligamentum flavum hypertrophy was identified in $50.8 \%$ (101 patients) of the cases. The gender breakdowns of intraoperative observations have been reported in the Table 3 . These observations concerned the anatomical elements which caused the lumbar spinal stenosis. This ligamentum flavum hypertrophy was present in $19.1 \%(n=38)$ of patients aged between 40 and 49 years old. The classification by age range of stenosis structures was reported in table 4. Figure 2 illustrates a LSS by a ligamentum flavum hypertrophy of a patient who underwent a laminectomy with canal enlargement. In 176 (88.4\%) cases, post-surgery outcomes were satisfactory. In $20(10 \%)$ cases there were complications. These complications were intraoperative in $9(4.5 \%)$ patients and postoperative in $12(6 \%)$. In 10 cases $(5 \%)$ it was dural tears with 4 cases of cerebrospinal fluid leak, which were all repaired in the same session. Postoperative wound infection was observed in $7(3.5 \%)$ which were treated with an adapted antibiotic after antibiogram. A new neurological deficit has occurred in $1(0.5 \%)$ case. Three patients $(1.5 \%)$ died. Two deaths occurred at the end of procedure. One due to heart failure and the other due to anesthesia failure. The third patient died because of a pulmonary embolism 5 days after surgery.

Table1 : Occupation of Patients
\begin{tabular}{|l|c|c|}
\hline \multirow{2}{*}{} & Frequency & Percentage \\
\hline Tradesmen & 56 & 28.1 \\
\hline Docker & 23 & 11.6 \\
\hline Housewife & 23 & 11.6 \\
\hline Soldiers & 15 & 7.5 \\
\hline State employee & 14 & 7 \\
\hline Labourer & 11 & 5.5 \\
\hline Health workers & 11 & 5.5 \\
\hline Pensioners & 10 & 5 \\
\hline Farmer & 9 & 4.5 \\
\hline Teacher & 7 & 3.5 \\
\hline dressmaker & 6 & 3 \\
\hline Religious* & 5 & 2.5 \\
\hline No Occupation & 5 & 2.5 \\
\hline Driver & 4 & 2.2 \\
\hline Total & 199 & 100 \\
\hline
\end{tabular}

*Priests, archbishop, sisters,

Table 2: Sign or Symptoms Seen during Neurological Examination of 199 Patients.

\begin{tabular}{|l|c|c|}
\hline & Frequency & Percentage \\
\hline Symptoms & & \\
Low back pain & 190 & \\
Bilateral radicular pain & 187 & 95.5 \\
Neurogenic claudication & 173 & 94 \\
Urinary urgency & 115 & 86.9 \\
Loss shoes & 92 & 57.8 \\
Sexual dysfunction & 43 & 46.2 \\
Bladder dysfunction & 40 & 21.6 \\
Unilateral radicular pain & 12 & 20.1 \\
& & 6 \\
& & \\
& & \\
Clinical signs & 160 & 80.4 \\
Spine stiffness & 145 & 73 \\
Reflex alterations & 90 & 45.2 \\
Spine Deformation & 31 & 15.6 \\
Motor deficit & 27 & 13.6 \\
Sensory changes & & \\
& & \\
&
\end{tabular}

Table 3. Intraoperative Finding Causing a LSS based on Gender Observed in 199 Patients

\begin{tabular}{|l|l|l|l|}
\hline & Men $\mathrm{n}(\%)$ & Women $\mathrm{n}(\%)$ & Total $\mathrm{n}(\%)$ \\
\hline Disc protrusion & $2(1)$ & $7(3.5)$ & $9(4.5)$ \\
\hline ZAJ hypertrophy* & $7(3.5)$ & $8(4)$ & $15(7.5)$ \\
\hline LF hypertrophy ** & $36(18.1)$ & $65(32.7)$ & $101(50.8)$ \\
\hline LJ/ZAJ* & $45(22.6)$ & $29(14.6)$ & $74(37.2)$ \\
\hline Total & $90(45.2)$ & $109(54.8)$ & $199(100)$ \\
\hline
\end{tabular}

ZAJ*: Zygoapophyseal Joint ; LF **: Ligamentum flavum 


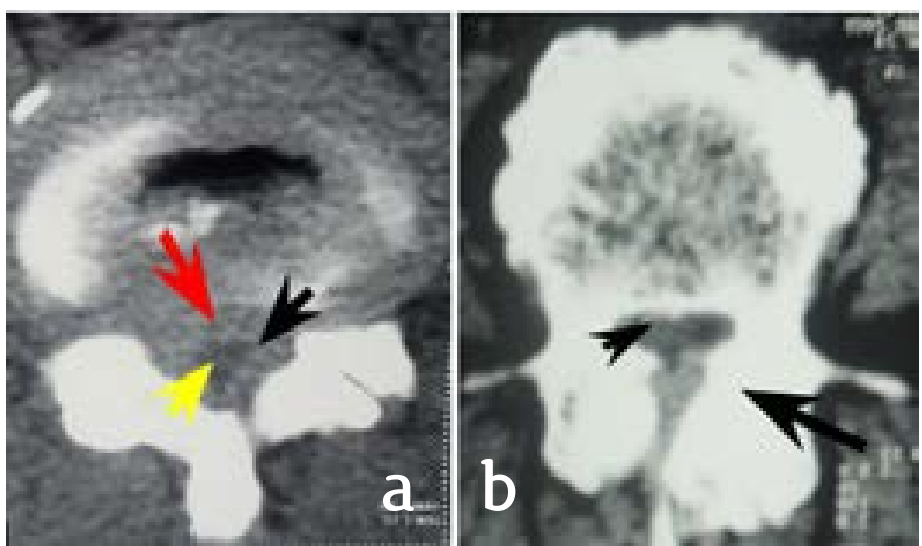

Figure 1. Axial lumbar CT-scan demonstrating acquired (a) and congenital (b) lumbar spinal stenosis.a) ligamentumflavum hypertrophy (yellow arrow), disc protrusion (red arrow) and severe narrowing of dural sac (black arrow) b) Congenital central and lateral LSS (short arrow) and aggravated by a zygapophyseal joint hypertrophy (long arrow)

\section{Discussion}

The anatomic presence of spinal stenosis is showed radiologically with computerized tomography (CT), myelography, or magnetic resonance imaging (MRI). Imaging enables to clearly specify the type of stenosis, the number of spine segments concerned and can also show bone and soft tissues concerned (5). The stenosis can be ventral by the intervertebral disc, dorsal by the ligamentum flavum hypertrophy, lateral by the zygapophyseal joint hypertrophy (3). Other causes (metabolic, traumatic, tumoral, and congenital) were also identified. In African series, it is already observed a decrease in the age in the occurrence of LSS. Kabré et al.(6) in Burkina-Faso; Oniankitan et al.(7) in Togo; Sanoussi et al.(8) in Niger reported respective mean age of 50.7 years, 51 years and 52 years. For these authors, hard works and everyday tough tasks accomplished would be responsible for earlier appearance of stenosis. Our study on 199 patients who underwent surgery enabled us to macroscopically explore the aetiology of the LSS in Black African. The two main anatomic intraoperative observations were the ligamentum flavum hypertrophy and the zygapophyseal joint hypertrophy $(95.5 \%)$ whether the stenosis were acquired, congenital or mixed. The stenosis was as well exclusively due to a ligamentum flavum hypertrophy $(50 \%)$ or the zygapophyseal joint hypertrophy $(7.5 \%)$. The two anatomic factors were combined in one third (37.1\%) of the cases. Kabré et al.(6) observed a respective exclusive implication of $41.3 \%$ and $27.5 \%$ of the ligamentum flavum and the zygapophyseal joint hypertrophy. Even if the zygapophyseal joint hypertrophy implication seems more predominant in the study reported by Kabré et al.(6), we observed a predominance of those two anatomic factors in the LSS cause in the Black African. Although Ridarch et al.(9) reported hypertrophy of the ligamentum flavum which they described as monstrous in young Caribbean's patients operated for LSS, Ba et al.(10) observed hypertrophy of the ligamentum flavum which they considered it physiologic on a series of 17 cases of spine autopsy performed on Senegalese patients. The hypertrophy of the ligamentum flavum considered physiologic can become pathological with aging, spine stress in combination with other anatomical structures (bone, discand ligament). These factors may becon genital or acquired $(3,5,11)$. According to Sakamaki

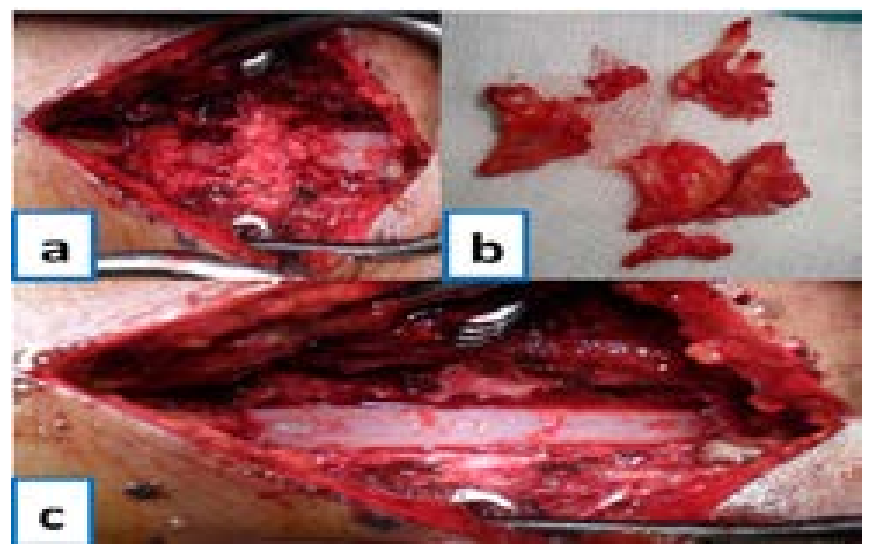

Figure 2. Intraoperative view of lumbar spinal stenosis a) hypertrophy of ligamentum flavum causing compression of the dural sac and narrowing of lumbar canal b) Macroscopic appearance of the ligamentum flavum after complete removal c) appearance of the dural sac after decompression and intraoperative view of the lumbar canal recalibration

et al.(11) or Truumees et al.(5) a hypertrophy of the ligamentum flavum observed since the 3rd and 4th decades would became pathological with the time and the conjunction of the anatomic bony factors, disc and ligamentous.

Whatever the anatomic factors found in our study, the difference observed were not statistically significant whatever data collected on age or gender. Similar findings were reported by Safak et al.(12) in Turkey on a series of 320 patients who had hypertrophy of ligamentum flavum and were explored with MRI, there was no significant statistical difference whether age or gender related. The role of the ligamentum flavum is then established in the occurrence of the LSS on Black African. According to Poonpukdee et al.(13), other than the age and mechanic stress related factors, the rise of the basic fibroblast growth factor would be the cause of ligamentum flavum hypertrophy, while Park et al.(14) mentioned an increase of proteinase inhibitor concentration of the ligamentum flavum extra cellular matrices degradation. As far as we know, there is no immunohistochemical study has been performed on Black Africans. Understanding and controlling all those factors would revolutionise care and treatment of LSS and enable a preventive anticipation $(15,16)$. Other factors such as degenerative disc disease and congenital LSS were reported in our study but appeared a small group of patients. These factors are decisive when associated $(1,2)$.

\section{Conclusion}

Lumbar spinal stenosis is frequent. It appears fromour intraoperative findings, the hypertrophy of ligamentum flavum and zygapophyseal joint are the most common causes among blacks Africans. Surgery remains usually the appropriate management. Further immunohistochemical studies may explain some hypotheses. This will broaden the therapeutic choices and enhance the prevention.

\section{Funding}

None declared.

\section{Conflicts of Interest}

The authors declare that they have no competing interests. 


\section{References}

1. Binder DK. Schmidt $M H$, Weinstein PR. Lumbar Spinal Stenosis. Seminars in Neurology 2002; 22 (2): 157-165.

2. Berney J. Epidémiologie des canaux lombaires étroits [French].Neurochirurgie 1994;40:174-8.

3. Botwin K.P., Gruber R.D. Lumbar spinal stenosis: anatomy and pathogenesis. Phys Med RehabilClin N Am 14 (2003) 1-15.

4. Fatigba $\mathrm{OH}$, Dovonou CA, Babio R, Odjo I, Padonou $\mathrm{J}$. low back pain in neurosurgery outpatients at Borgou departmental hospital, Benin. Epidemiological and etiological aspects about 209 cases [French]. Daka Med. 2011;56(3): 366-372.

5. Truumees E. Spinal stenosis: pathophysiology, clinical and radiologic classification. Instr Course Lect. 2005; 54:287-302.

6. Kabré, A, Ba, M. C, Cissé, R, SorghoLougue C, Dolip $\mathrm{P}$, Kaboré, J. Lumbar canal stenosis in Ouagadougou: aetiological, clinical aspects and prognosis about 80 cases [French]. Dakar Médical2003; 48(2): 138-41.

7. Oniankitan O, Magnan A, Fianyo E, Mijiyawa M. Lumbar canal stenosis in rheumatologic outpatients at Lomé [French]. (Togo). Med Trop 2007;67:263-6

8. Sanoussi S, bawa M, Maman Sani R, Guemou,A BoureimaM. Management of lumbar spinal canal in Niamey [French]. Revue internationale de médecine de Côte d'lvoire 1996; 13: 197-201.

9. Ridarch A, Bazin M, Elisabeth L.: Morphological characteristics of the lumbar and cervical canal in the Caribbean [French]. Bull. Soc. Anat.1983;8:49-59.

10. Ba M.C, Ndiaye A, Badiane S.B, Sakho Y, Badiane M, Guèye E.M, Ba-LyA, Sow M.L, Guèye M.: Biometric aspects of vertebral lumbar canal of senegalese negro african[French]. Dakar Médical, 1994, 39 (2), 199-202.

11. Sakamaki T, Sairyo K, Sakai T, Tamura T, Okada Y, Mikami H. Measurements of ligamentumflavum thickening at lumbar spine using MRI.Arch Orthop Trauma Surg. $2009 ; 129(10): 1415-9$.

12. Safak $A A$, Is $M$, Sevinc $O$, Barut $C$, Eryoruk $\mathrm{N}$, Erdogmus $\mathrm{B}$, Dosoglu $\mathrm{M}$. The thickness of the ligamentumflavum in relation to age and gender. Clin Anat. 2010;23(1):79-83.

13. Poonpukdee J, Chalermpanpipat $\mathrm{C}$, Payungporn S, Honsawek S. Basic fibroblast growth factor expression in hypertrophic ligamentumflavum of lumbar spinal stenosis. Asian Biomedicine 2012; 6(1): 99-104.

14. Park JB., Lee JK., Park SJ., Riew D. Hypertophy of ligamentumflavum in lumbar spinal stenosis associated with increased proteinase inhibitor concentration. The journal of bone and joint surgery 2005;87(12):2750-2756.

15. Genevay S, Atlas SJ. Lumbar Spinal Stenosis. Best Practice \& Research Clinical Rheumatology 2010; 24: 253-265.

16. Yoshida $M$, Shima $K$, Taniquchi $Y$, et al. Hypertrophied ligamentumflavum in lumbar spinal canal stenosis. Pathogenesis and morphologic and immunohistochemical observation. Spine 1992;17(11):1353-60.

\section{Comments}

This observational study has been designed with the aim of defining the etiology of lumbar spinal stenosis (LSS) in a predefined population of black Africans. The authors have extracted the data available in the files of 199 patients operated in their department and tried to resume a kind of correlation between their findings and what is called 'etiology' of the illness. We would like to suggest the followings a) The title cannot explain what is summarized in the results but the second sentence in the 'objectives' can be the most appropriate title for this article e.g. 'Intraoperative surgical findings of 199 cases of black Africans operated for LSS. A retrospective review' b) The main issue would be, how much such findings were extraordinary in comparison with others regarding the race and geographical context of the target population? Such a study needs a thorough review of both old and new literature in a systematic way which is difficult and needs exact review of the literature.

Kazem Abbassioun MD, Professor of Neurosurgery, Vice-president of Iranian Association of Surgeons, Tehran, Iran

Abbas Amirjamshidi MD. MPH, Professor of Neurosurgery, Department of Neurosurgery, Sina Hospital Tehran University of Medical Sciences (TUMS), Tehran, Iran

Holden O. Fatigba and colleagues described 199 black Africans who operated for lumbar spinal stenosis (LSS) at the Departmental Teaching Hospital of Borgou in Benin (West Africa) from January 2008 to June 2014 (1). The study design was retrospective. The male to female ratio was 1.21 . Degenerative or acquired was the most common type of LSS, which was seen in $78.9 \%$ of the patients and was associated with hypertrophy of ligamentum flavum in 101 patients (50.8\%). However, a congenital type of LSS was diagnosed by zygapophyseal joint hypertrophy in 15 cases $(7.2 \%)$. There were mixed types in 74 patients $(37.2 \%)$. The authors excluded patients with extruded lumbar discopathy. They mentioned satisfactory outcomes in $88.4 \%$ and a few cases of dural tear and CSF leak and post operative infections and $1.5 \%$ death.

This study is an addition to the literature. We would appreciate studies from Africa which there are rare reported series. However, there are few concerns: First, a major weak point of the study is the retrospective design. Therefore, the authors did not have a well defined program to use specific questionnaire for outcome measures and the accurate evaluation of patients in the short and long term. It is not possible to register the accurate post operative pain, neurogenic intermittent claudication and neurologic deficits. It is not well defined the meaning of satisfaction. To remove bias, an independent observer has to evaluate satisfaction and post operative signs and symptoms. These can be performed in well prepared prospective study.

Second, authors emphasized on a case series from black African. However, we cannot find any specific epidemiological finding to show a definite difference between black African and other races in this study.

Third, research starts with a well-defined question. We would suggest the authors design an analytical observational study based on a well-prepared question. For example, what are the surgical hospitalization rates for LSS among different races? (2) Are there any racial disparities in the rate of complications, length of stay, and costs after surgery for LSS? (3) Are there any difference among different races for long-term post operative pain and functional assessment of patients operated for LSS, the best design would be a multicentre prospective cohort study for more than five years duration. However, before decision on the study design, we need to perform a literature search. Therefore, first step is to develop a well-defined question. Second step is to perform study search. Third step is to find an appropriate study design. Before initiation of the study, other steps are find measures, analysis, resource and timing, and reduction of bias (4).

Vafa Rahimi-Movaghar, MD, Professor of Neurosurgery, Sina Trauma and Surgery Research Center, Tehran University of Medical Sciences, Tehran, Iran

Alexander $R$ Vaccaro, $M D, P h D$, Professor of Orthopedics, The Rothman Institute at Thomas Jefferson University, Philadelphia, PA, USA

\section{References:}

1. Fatigba $\mathrm{O} \cdot \mathrm{H}$, Hans-Moevi AA, Belo $M$, Savi de Tové K, Pape A.G. Mijiyawa M. Aetiology of the Lumbar Spinal Stenosis in Black Africans: Intraoperative Observations. IrJNS. 2015;1(1):35-38.

2. Skolasky RL, Maggard AM, Thorpe RJ Jr, Wegener ST, Riley LH 3rd. United States hospital admissions for lumbar spinal stenosis: racial and ethnic differences, 2000 through 2009. Spine (Phila Pa 1976). 2013;38(26):2272-8.

3. Lad SP, Bagley JH, Kenney KT, Ugiliweneza B, Kong M, Bagley CA, Gottfried ON, Isaacs RE, Patil CG, Boakye M. Racial disparities in outcomes of spinal surgery for lumbar stenosis. Spine (Phila Pa 1976). 2013;38(11):927-35.

4. Lee, Michael J; Norvell, Daniel C; Dettori, Joseph R; Andrea C. Skelly, Jens R. Chapman. Thieme Medical Publishers. SMART Approach to Spine Clinical Research: 2013 DOI 10.1055/b-002-91657 Print ISBN 9783131750617 • Online ISBN 9783131750716 